\title{
Właściwości tytanowej powłoki metalizacyjnej osadzanej tarciowo na ceramice AIN
}

\author{
Properties of titanium coatings deposited \\ by friction processing onto AIN ceramics
}

\section{Streszczenie}

W pracy przedstawiono wybrane właściwości tytanowej powłoki metalizacyjnej wytworzonej na ceramice AIN metodą tarciową opierając się na mechanizmie powstawania połączenia, w którym energia tarcia kinetycznego jest bezpośrednio zamieniana na ciepło i dostarczana w ściśle określonej ilości do obszaru powstającego połączenia między warstwą a podłożem. W artykule scharakteryzowano tytanową powłokę metalizacyjną pod względem budowy fazowej, właściwości metalograficznych, morfologii powierzchni, struktury stereoskopowej powierzchni oraz grubości.

Słowa kluczowe: powłoki; metalizacja ceramiki; metalizacja tarciowa; złącza ceramika-metal

\begin{abstract}
The paper presents selected properties of titanium coating deposited onto AIN ceramic surface using friction method based on a mechanism of joint formation, where the energy of kinetic friction is directly transformed into heat and delivered in a specified amount directly to the created joint between layer and substrate material. Face structure, metallographic properties, morphology and stereoscopy structure and thickness have been investigated.
\end{abstract}

Keywords: coatings; metallization of ceramics; friction metallization; ceramic-metal joints

\section{Wstęp}

Zastosowanie ceramiki azotkowej w tym AIN w technice, podobnie jak wielu innych zaawansowanych materiałów ceramicznych, wymaga wytwarzania złączy ceramiczno-me-

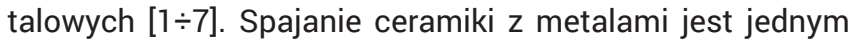
z najtrudniejszych zadań w inżynierii spajania. Trudności spajania przedstawionej pary materiałów, wynikają ze skrajnych odmienności właściwości fizycznych i chemicznych materiałów ceramicznych i metalowych. Największe niedopasowanie ceramik i metali z punktu widzenia powstania połączenia dotyczy przede wszystkim różnych wiązań atomowych. Wynikająca m.in. z tego niska zwilżalność powierzchni ceramiki przez większość ciekłych metali. Równie istotne dla właściwości powstałego złącza są również skrajnie różne wartości współczynnika rozszerzalności cieplnej, współczynnika przewodnictwa cieplnego.

We wszystkich przypadkach spajania ceramiki z metalami $[8,9]$ podczas procesu łączenia ceramika pozostaje w stanie stałym, a bardzo często łączony do niej metal jest topiony. Zaprezentowana w niniejszym artykule powłoka metalizacyjna została wykonana metodą tarciową, która umożliwia powstanie połączenia pomiędzy ceramicznym podłożem i powłoką metalizacyjną, gdzie podczas procesu łączenia oba materiały pozostają w stanie stałym. Możliwość utrzymania metalu powstającej powłoki $\mathrm{w}$ stanie stałym, charakteryzującego się wysoką plastycznością wynika z doprowadzania energii do obszaru spajania na drodze mechanicznej. Taki sposób nagrzewania umożliwia precyzyjne sterowanie ilością doprowadzanej energii oraz ograniczenie nagrzewania łączonych przedmiotów jedynie do obszaru powstającego złącza. [1,2,10].

Celem wytwarzania cienkiej powłoki tytanowej jest metalizacja powierzchni ceramiki ułatwiającej w następstwie właściwe spajanie (np. lutowanie) ceramicznych przedmiotów z innymi metalowymi za pośrednictwem przedmiotowej powłoki tytanowej. Tytan jako materiał powłoki metalizacyjnej zastosowano z powodu jego znacznej aktywności chemicznej w stosunku do podstawowych składników różnych gatunków ceramiki w tym glinu i azotu $[2,6 \div 9]$.

\section{Warunki wytwarzania tytanowej powłoki metalizacyjnej na ceramice AIN}

Osadzana na powierzchni ceramiki powłoka, była wytwarzana poprzez obrotowe tarcie czołem (wskazane strzałką na rys. 1) tytanowego (Grade 2) narzędzia w kształcie walca (rys.1) o zewnętrznej średnicy $9 \mathrm{~mm} z$ otworem $3 \mathrm{~mm}$ w osi. Obracające się narzędzie dodatkowo wykonywało ruch postępowy liniowy lub spiralny w celu uzyskania powłoki o powierzchni znacznie większej niż powierzchnia robocza narzędzia (rys. 3 i 4). Opisane narzędzie zostało zamontowane

Mgr inż. Michał Hudycz; dr hab. inż. Tomasz Chmielewski, prof. PW; mgr inż. Maciej Winiarski; dr hab. inż. Dariusz Golański, prof. PW - Instytut Technik Wytwarzania, Politechnika Warszawska.

Autor korespondencyjny/Corresponding author. t.chmielewski@wip.pw.edu.pl 
w oprawce umożliwiającej przeniesienie momentu obrotowego oraz kontrolowanie nacisku na powierzchni tarcia. Mechanizm powstawania powłoki polega rozcieraniu materiału czoła narzędzia na powierzchni ceramiki. Literatura przedmiotu wskazuje że podczas spajania w stanie stałym możliwe jest uzyskanie trwałych złączy materiałów skrajnie różniących się właściwościami zarówno fizycznymi jak i cemicznymi $[1 \div 5,12,13]$. W celu uniknięcia utlenienia tytanu obszar roboczy otoczono cylindryczną barierą do wnętrza której dostarczano argon z natężeniem przepływu 5l/min. zapewniając stężenie tlenu poniżej 5 ppm.

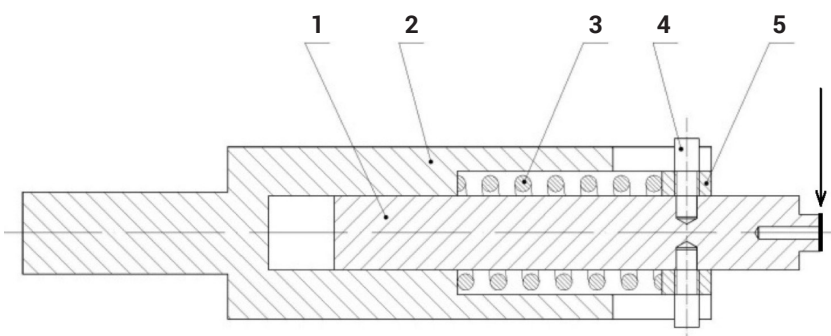

Rys. 1. Szkic tytanowego narzędzia w oprawce 1) narzędzie, 2) oprawka, 3) sprężyna, 4 i 5 elementy regulacji napięcia sprężyny Fig. 1. Schema of Ti friction tool in holder. 1) friction tool, 2) holder, 3) spring, 4 and 5 spring tension adjustment items

Proces metalizowania tarciowego został wykonany na numerycznym centrum obróbczym Arrow 500 firmy Cincinnati, zamocowane podłoże i narzędzie podczas procesu wytwarzania powłoki przedstawia rysunek 2 .

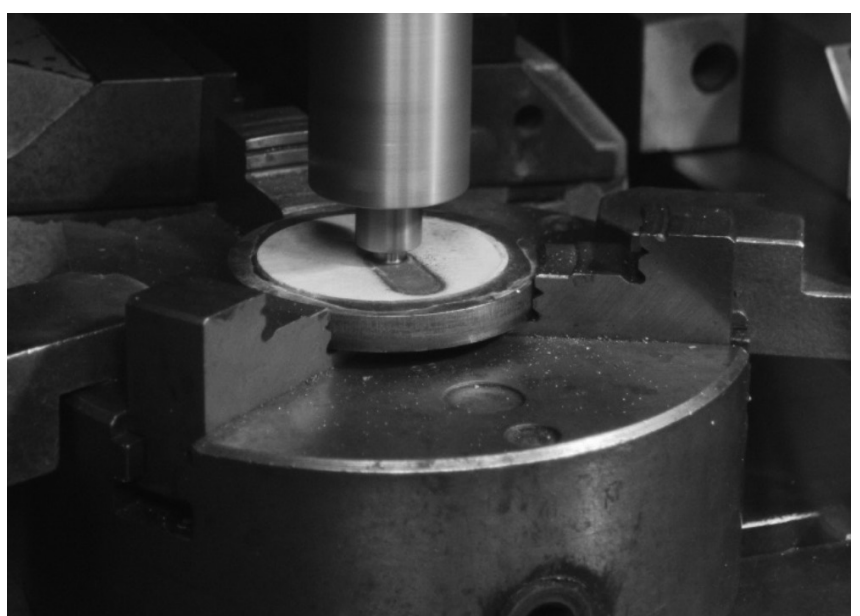

Rys. 2. Narzędzie pracy oraz widok powstającej powłoki

Fig. 2. The tool friction during operation and a view of the emerging coating

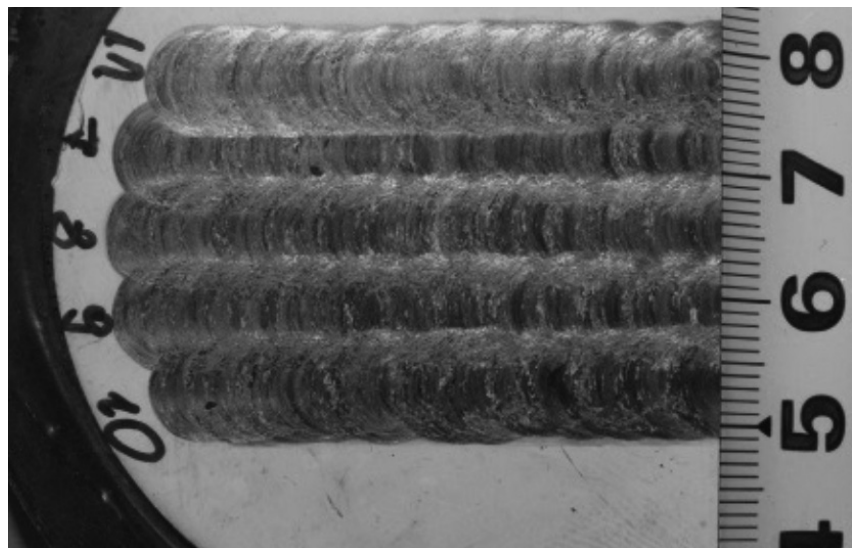

Rys. 3. Powłoka składająca się z kilku ściegów prostych wykonanych z zakładką

Fig. 3. Coating consists of few passes with overlapping

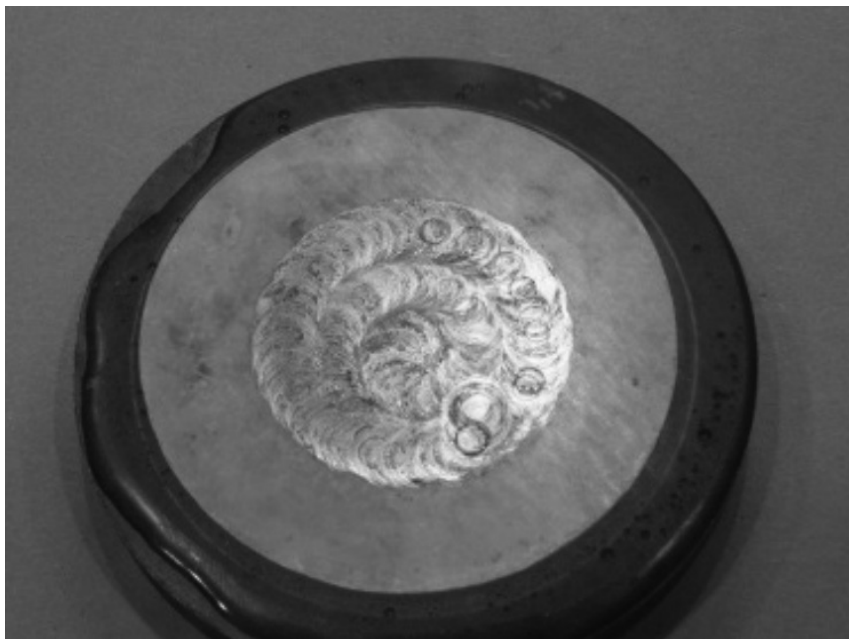

Rys. 4. Powłoka wykonana ściegiem spiralnym

Fig. 4. Coating produced by spiral passes

\section{Budowa mikrostrukturalna powłoki}

Na rysunku 5 pokazano mikrostrukturę złącza ceramicznego podłoża (AIN) z metaliczną powłoką (Ti). Obserwacje SEM prowadzono na powierzchni przełomu uzyskanego z trójpunktowego zginania próbki (rozciąganie po stronie powłoki), będącego jednocześnie wymagającym testem przyczepności powłoki. Materiał powłokowy jest bardzo dobrze połączony z podłożem i skutecznie wypełnia nierówności podłoża. Po próbie łamania nie zaobserwowano wykruszania się go w obszarze połączenia. Struktura podłoża wykazuje cechy charakterystyczne dla ceramiki AIN będącej spiekiem odrębnych ziarem AIN z charakterystyczną porowatością. W strukturze podłoża nie zaobserwowano pęknięć wywołanych procesem tarciowej metalizacji. Grubość powłoki zawiera się w przedziale od około 3 do $6 \mu \mathrm{m}$. Powłoka tytanu szczelnie pokrywa ceramikę, a w jej objętości widoczne są liczne wtrącenia submikrometrycznych ziaren ceramiki pochodzących z powierzchni tarcia, których obecność i dystrybucja w powłoce świadczą o wysokim stopniu uplastycznienia ziaren tytanu podczas wytwarzania powłoki. Obecność aluminium w powłoce potwierdzają również rozkłady liniowe pierwiastków na powierzchni przekroju układu podłoże-powłoka, zaprezentowane na rysunku 6. Charakter zmian stężenia tytanu i glinu w granicy międzyfazowej AIN-Ti nie wskazuje na obecność strefy przejściowej.

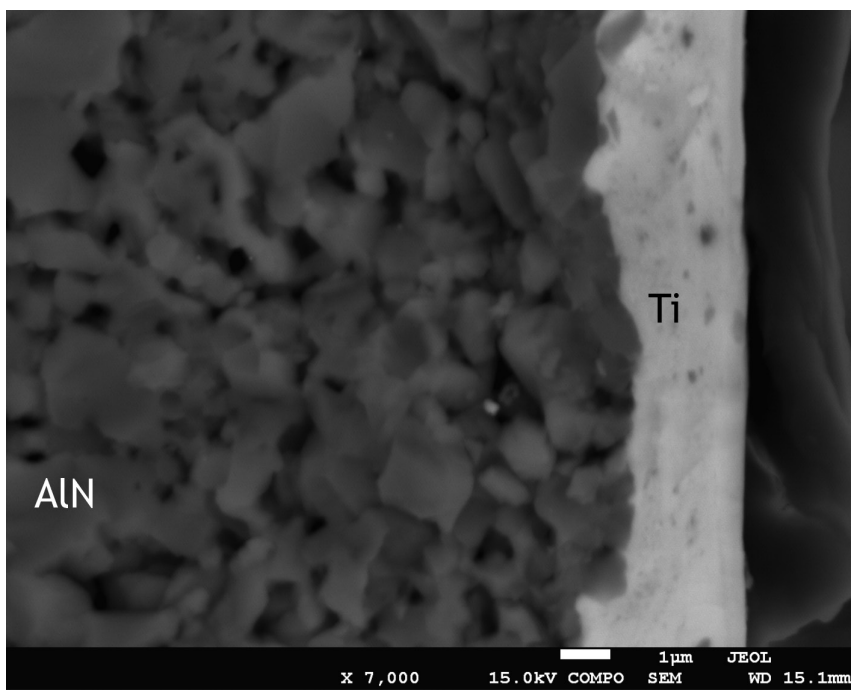

Rys. 5. Obraz SEM przekroju układu podłoże AIN-powłoka Ti Fig. 5. SEM view of cross section przez thru substrate AIN-coating Ti system 


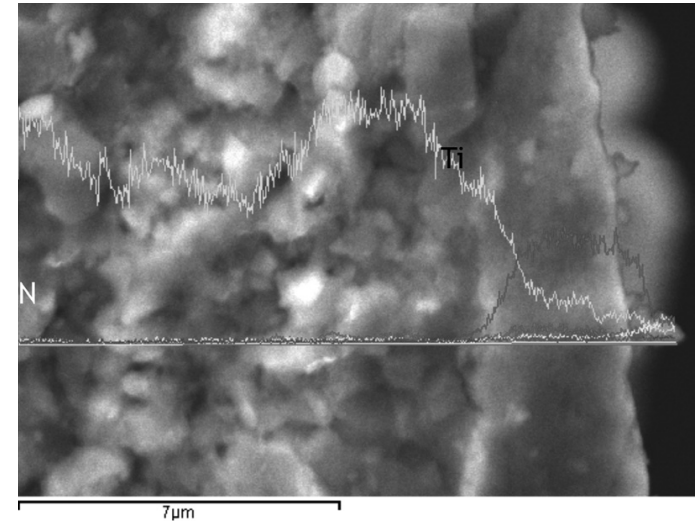

Rys. 6. Rozkład liniowy pierwiastków na powierzchni przekroju układu podłoże-powłok

Fig. 6. Linear distribution of elements on the surface of cross-section through the substrate and coating system

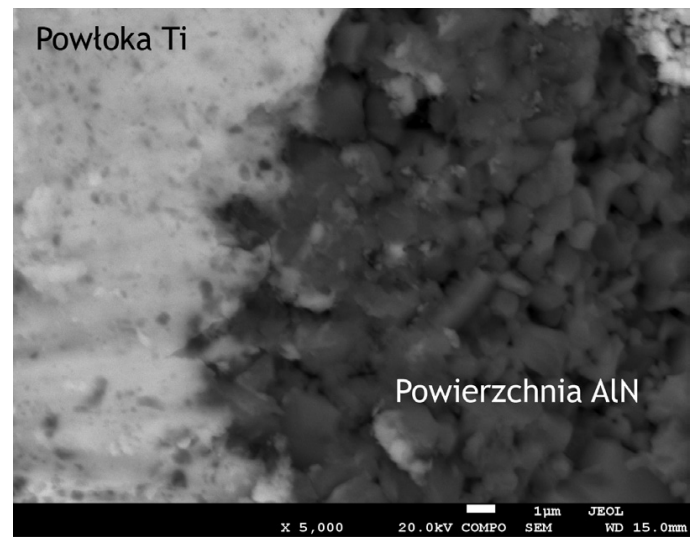

Rys. 7. Obraz powierzchni na granicy tytanowej powłoki metalizacyjnej Fig. 7. View of surface on border of titanium metallization coating

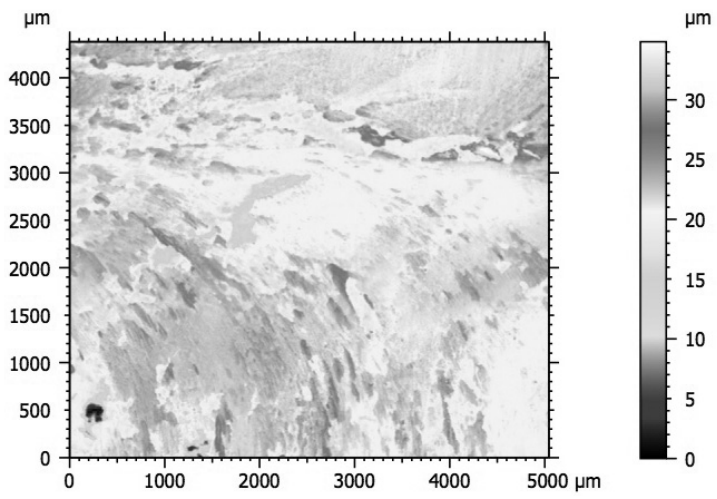

Rys. 8. Obraz powierzchni na granicy tytanowej powłoki metalizacyjnej Fig. 8. View of surface on border of titanium metallization coating

\section{Struktura stereometryczna warstwy wierzchniej powłoki}

Pomiary geometrii powierzchni prowadzono na optycznym profilometrze skaningowym $\mu$ scan select firmy Nanofocus. Parametry przeprowadzonego pomiaru: pole pomiarowe (kierunek x) $5 \mathrm{~mm}$ x (kierunek y) 4,5 mm. Wyznaczono parametry chropowatości powierzchni po filtracji - Gauss $0,08 \mathrm{~mm}$ oraz wykonano mapę stereometryczną badanych powierzchni, przedstawioną na rysunku 8. Struktura powierzchni wszystkich badanych powłok natryskiwanych jest
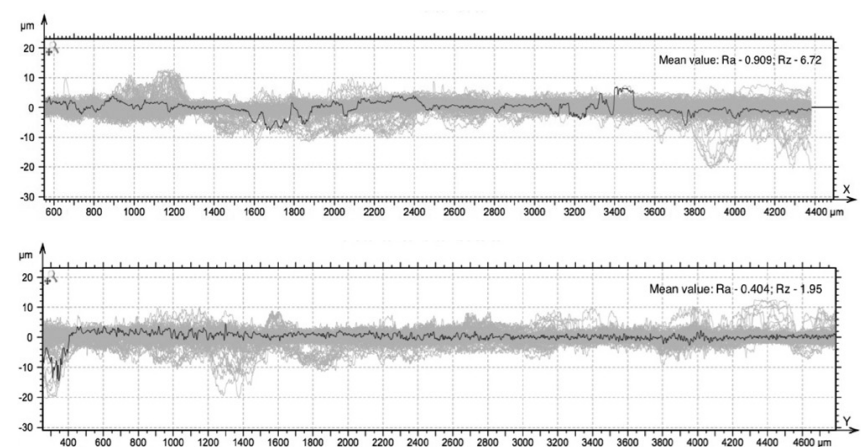

Rys. 9. Zestawienie uzyskanych profili chropowatości w kierunkach: a) $-x, b)-y$

Fig. 9. Roughness graphs and profiles in direction : a) $-x, b)-y$

anizotropowa, wykazuje wyraźną kierunkowość wzniesień i wgłębień, będącą odwzorowaniem obrotowego z jednoczesnym posuwem ruchu narzędzia. Na rysunku 9 przedstawiono wykresy prezentujące chmurę wszystkich zarejestrowanych profili chropowatości w kierunkach x oraz y. Pokazano również pojedyncze profile dla obu kierunków uzyskane po środku badanego pola oraz średnią wartość Ra i Rz dla wszystkich pomiarów w obu kierunkach.

\section{Analiza fazowa tytanowej powłoki metalizacyjnej}

Analiza fazowa powłoki metalizacyjnej wskazuje na stosunkowo wysoką jednorodność struktury metalicznej osnowy powłoki składającej się w większości z czystego tytanu, praktycznie amorficznego (daje bardzo rozmyty sygnał dyfrakcyjny). W strukturze powłoki obecne są również ziarna AIN zatarte z powierzchni ceramiki podczas pracy narzędzia. Nic nie wskazuje na to, by podczas zgrzewania powstała w połączeniu wyraźna dyfuzyjna warstwa pośrednia.

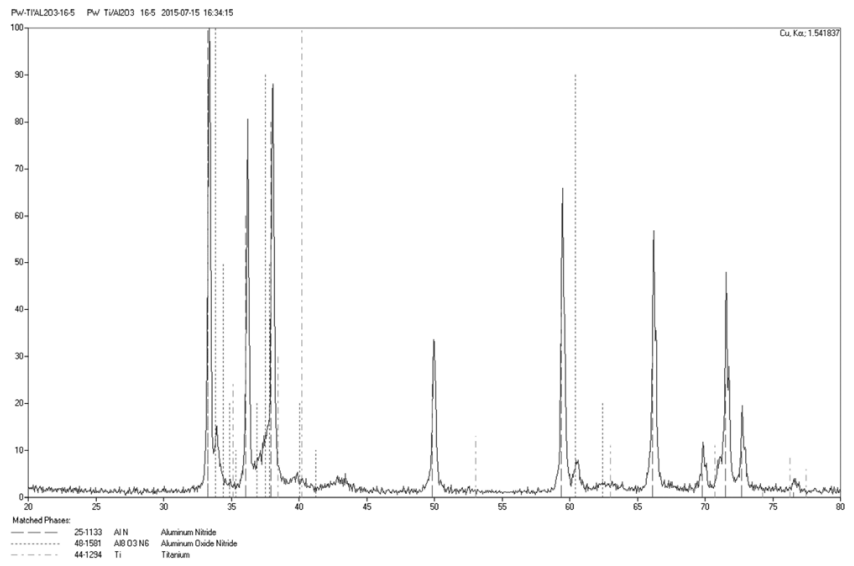

Rys. 10. Dyfraktogram powłoki Ti osadzonej tarciowo na ceramice AIN

Fig. 10. Diffractogram of Ti coating deposited onto AIN ceramics substrate 


\section{Podsumowanie i wnioski}

Osobliwe właściwości materiałów ceramicznych i wynikające z tego trudności łączenia ich z metalami stanowią ważny problem technologiczny. Pomimo licznej grupy opracowanych już metod i technik spajania ceramiki z metalami, otrzymywanie w skali przemysłowej złączy ceramiczno-metalowych o wysokich właściwościach eksploatacyjnych, wciąż będzie przedmiotem intensywnych badań. Obecnie powstaje wiele nowych koncepcji wytwarzania połączeń ceramika-metal, jednak ze względu na znaczne różnice we właściwościach komponentów, wszystkie metody spajania są dość kłopotliwe w masowej produkcji.

Z przeprowadzonych doświadczeń zarysowuje się możliwość wykonywania przydatnej i atrakcyjnej pod względem ekonomicznym metalizacyjnej powłoki tytanowej na powierzchni AIN. Pod warunkiem zastosowania argonowej ochrony gazowej istnieje możliwość wyeliminowania ryzyka utlenienia tytanu pomimo nagrzewania tytanu do stosunkowo wysokiej temperatury. Uzyskana powłoka jest szczelna, dobrze związana z podłożem, jej struktura stereometryczna i budowa fazowa sprzyjają zwilżalności klasycznymi lutami np. AgCu28.

\section{Literatura}

[1] [1] M. Hudycz, M. Winiarski, T. Chmielewski: Tarciowe metalizowanie ceramiki AIN tytanem, Przegląd Spawalnictwa, vol. 87, nr 10, s. 31-35, 2015.

[2] T. Chmielewski: Wykorzystanie energii kinetycznej tarcia i fali detonacyjnej do metalizacji ceramiki, Prace Naukowe PW, seria Mechanika, Zeszyt 232, pp. 1-155. 2012

[3] T. Chmielewski: Natryskiwanie detonacyjne metali na podłoża ceramiczne, Przegląd Spawalnictwa, vol.78, nr 9-10, s.80-83, 2006.

[4] W. Włosiński, T. Chmielewski, M. Kucharczyk: Spajanie tarciowe stopów NiAl i FeAl ze stalą węglową St3S, Przegląd Spawalnictwa, vol.75, nr 1, s.6-12, 2004.

[5] K. Pietrzak, D. Kaliński, M. Chmielewski, T. Chmielewski, W. Włosiński, K. Choręgiewicz: Processing of intermetallics with Al2O3 or steel joints obtained by friction welding technique, 12th Conference of the European Ceramic Society - ECerS XII, Stockholm, 2011.

[6] W. Włosiński, T. Chmielewski, A. Grabowska, A. Góra: Warunki spajania tarciowego i struktura złączy Al2O3-Al i Al2O3-Cu, Przegląd Spawalnictwa, vol.75, nr 12, s. 1-5, 2003

[7] A. Krajewski, M. Barlak, M. Hudycz, T. Chmielewski: Spajanie ceramiki korundowej modyfikowanej impulsami plazmy DPE + arc PVD, Prace Naukowe Programu Priorytetowego Nowe Technologie, zeszyt 5 s. 49-58, 2002.
[8] M. Barlak, T. Chmielewski, M. Hudycz, A. Krajewski, W. Włosiński: Nowe metody spajania materiałów ceramicznych i metalowych, Prace Naukowe Programu Priorytetowego Nowe Technologie, zeszyt 4 s. 107-116, 2001.

[9] M. Ossowski, M. Hudycz, T. Wierzchoń: Struktura i właściwości kompozytów warstwowych: stop tytanu-fazy międzymetaliczne z układu Ti-Al Przegląd Spawalnictwa, vol. 79, nr 8, s. 13-16, 2007.

[10] A. Krajewski, M. Hudycz: Wytrzymałość złączy ceramiczno-metalowych, Przegląd Spawalnictwa, vol.73, nr 8-9, s.50-53, 2001

[11] T. Chmielewski, D. Golański, W. Włosiński, J. Zimmerman: Utilizing the energy of kinetic friction for the metallization of ceramics, Bulletin of the Polish Academy of Sciences Technical Sciences vol. 63, No 1, pp. 201207, 2015.

[12] G. Rogalski, D. Fydrych, W. Walczak: Wpływ cyklu cieplnego na właściwości zgrzewanych wybuchowo złączy stal-aluminium, Przegląd Spawalnictwa, Vol. 85, nr 6, s. 60-54, 2013.

[13] G. Rogalski, D. Fydrych, W. Walczak: Zastosowanie zgrzewania wybuchowego do wytwarzania kompozytów metalowych z osnową ceramiczną, Przegląd Spawalnictwa, Vol. 85, nr 6, s. 54-59, 2013. 